\title{
REGIONAL DISPARITIES IN BULGARIA AND EU COUNTRIES
}

\author{
S. Totev* \\ Faculty of Economics, Trakia University, Stara Zagora, Bulgaria
}

\begin{abstract}
The realization of economic convergence of the new member states is one of the biggest challenges that face EU. It raises important questions and problems for research; to determine what processes of regional development are taking place within the Union. In this regard, a key issue that arises and is related to the Bulgarian integration to the economic structures of the EU is the extent to which these processes have an impact on Bulgarian regional development. By applying statistical and economic methods the paper attempts to analyse these processes in the light of similar processes in the EU as a whole and by particular countries - to highlight the general and specific features in the Bulgarian regional development. According the "EU Regional Social Progress Index" and some of its sub-indices the specific places that occupy the Bulgarian regions on NUTS 2 among all other regions of the EU countries are compared and analysed. Based on the obtained results some policy implications are made.
\end{abstract}

Key words: Regional policy; EU cohesion policy; Comparative economics.

\section{INTRODUCTION}

A major issue that arises and relates to the integration of Bulgaria into the EU's economic structures is the degree to which the observed processes are related to changes in internal socio-economic regional disparities. The integration and the related convergence of the less developed countries within the EU leads as rule to an increase of the regional differences, (Totev, S. 2010). Along with reducing national disparities between EU countries measured by GDP per capita, a clear trend of convergence to the average European level is observed in all Central and Eastern European countries measured by the ratio of GDP per capita in PPS (Purchasing power parity) - the only exception is the Republic of Croatia /see Eurostat: GDP per capita in PPS EU $28=100-$ Eurostat is the source for the presented data in the paper/. However, as a rule, indicators for intra-regional dispersion increase for most socio-economic characteristics in less developed EU countries, (the dispersion is measured by the coefficient of variation $\mathrm{V}=\sigma / \overline{\boldsymbol{x}} * 100$ - GDP per capita standard deviation divided by the average GDP per capita, in percent). Thus, at NUTS 2 level

\footnotetext{
*Correspondence to: $S$. Totev, Faculty of Economics, Trakia University, Stara Zagora, Bulgaria, 4, "Tzanko Tserkovski” Street, 1164 Sofia,E-mail:stotev@yahoo.com,Mobile phone: $+359889625968$
}

(statistical regions in Bulgaria) if the coefficient of variation within EU countries is $19.7 \%$ in 2000 , it is $22.4 \%$ in 2011 - for NUTS 3 level are respectively $25.9 \%$ and $28.3 \%$.

\section{REGIONAL DISPARITIES IN BULGARIA IN THE EU FRAMEWORK}

Typical for the Central and East European EU countries with weaker economies is the process of regional disparities increasing, the correlation coefficient between regional dispersion per country and per capita GDP is negative: for NUTS 2 and NUTS 3 it is minus 0.31 and minus 0,49 in 2004 and become in 2011 respectfully minus 0.52 and minus 0.56 . In other words, there is a clear reversed relationship between the economic level reached and the intra-regional dispersion. For example, for Bulgaria, if the dispersion indicators are not high for 2000 at NUTS 2 level it is $18.1 \%$ with the EU average of $19.7 \%$, respectively at NUTS 3 level $27.3 \%$ with the EU average of $22.4 \%$ (11 countries have higher coefficients of variation than Bulgaria's NUTS 3 level in 2000). The picture in 2011 is radically changed, for NUTS 2 and NUTS 3 the respective magnitudes are $39.2 \%$ and $42.5 \%$, as in both cases, they are the highest in the EU Member States, (the coefficient of variation for Bulgaria in 2015 is already $50 \%$.). The increase of the coefficient of variation at NUTS 3 level compared to 2000 for Bulgaria is $67 \%$ - for comparison, Romania 
is the country that has the highest growth after Bulgaria but it is only $31 \%$ (columns 13 and 14 of Table 2).

Although these high regional disparities in terms of per capita GDP are not associated with high disparities in the dispersion of the unemployment indicator (an indicator that is lower than the EU average for Bulgaria - the dispersion of the unemployment rate is measured in a similar way, as the dispersion of GDP). It is obvious that they pose a serious risk of reaching undesirable regional economic and social disparities - leading to income disparities, unwished migration and all associated with that negative consequences.
Table 1 presents the positioning of the Bulgarian's NUTS 2 regions to all regions of EU countries at NUTS 2 level according to the EU Regional Social Progress Index and some of its sub-indices, (the European Union Regional Social Progress Index measures social progress on 50 indicators across the 272 regions of the 28 European Union member states). They determine the unenviable positions occupied by the statistical regions in Bulgaria, not only in terms of the general index, but also to the other observed indices, except for the "environmental quality" indicator.

Table 1. Level and position of the regions in Bulgaria in relation to all regions in the EU according to the "EU Regional Social Progress Index" and selected sub-indices

\begin{tabular}{|c|c|c|c|c|c|c|c|c|c|c|}
\hline $\begin{array}{l}\text { NUTS } 2 \\
\text { Regions }\end{array}$ & 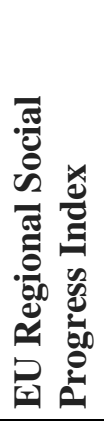 & 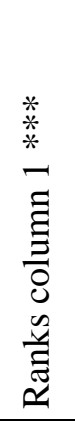 & 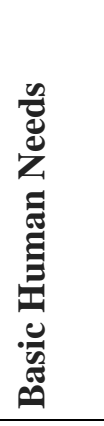 & 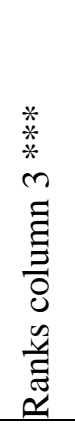 & 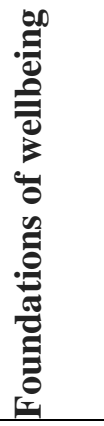 & 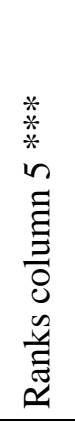 & 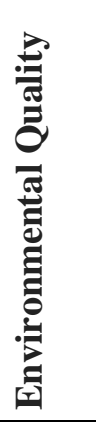 & 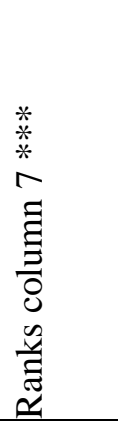 & 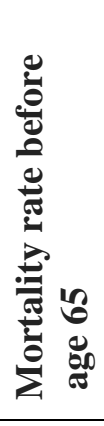 & 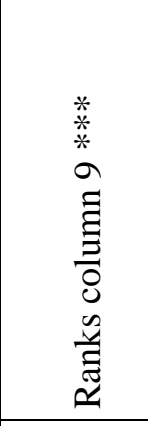 \\
\hline Columns & 1 & 2 & 3 & 4 & 5 & 6 & 7 & 8 & 9 & 10 \\
\hline Northwest & 40,6 & 2 & 44,7 & 5 & 47,0 & 7 & 49,3 & 178 & 0,27 & 4 \\
\hline North central & 46,2 & 8 & 47,3 & 7 & 49,3 & 13 & 45,0 & 133 & 0,25 & $12-16$ \\
\hline Northeast & 45,7 & 7 & 46,3 & 6 & 46,7 & 6 & 43,3 & 114 & 0,25 & $12-16$ \\
\hline Southeast & 39,7 & 1 & 42,5 & 1 & 45,8 & 4 & 49,1 & 176 & 0,26 & $5-11$ \\
\hline Southwest & 50,7 & 15 & 52,8 & 14 & 54,8 & 46 & 39,4 & 71 & 0,23 & $19-24$ \\
\hline South central & 44,2 & 6 & 47,9 & 8 & 49,7 & 17 & 47,2 & 159 & 0,23 & $19-24$ \\
\hline Average* & 66,5 & 110 & 76,8 & 101 & 62,1 & 113 & 46,4 & 148 & 0,14 & $71-92$ \\
\hline Maximum ** & 82,3 & 272 & 90,3 & 272 & 76,1 & 272 & 91,1 & $270-2$ & 0,08 & $270-2$ \\
\hline Minimum $* *$ & 39,7 & 1 & 42,5 & 1 & 42,3 & 1 & 20,6 & 1 & 0,30 & 1 \\
\hline
\end{tabular}

Source: Eurostat

* Arithmetical average not-weighted for the 272 NUTS 2 regions in EU;

** Maximum and minimum meanings and their ranks;

*** The lowest rank 1 corresponds to the most unfavourable value of the indicator.

It is interesting that within EU countries the general "EU Regional Social Progress Index" has a positive correlation with the environmental index, whereas in the case of Bulgaria the relation is reversed. In this sense, while having the higher ranking of this general index is associated with better environmental protection on the whole for EU countries, in the case of Bulgaria the relations is negative. The interpretation of this coefficient of correlation literally means that regional development in Bulgaria is at such a stage that the achievement of a higher position with the EU Regional Social Progress Index is associated with a certain deterioration in the quality of the environment. However, such a statement must be accepted with some reservations without being based on more comprehensive information.

The observed regional differences in Bulgaria are the result of intensive development of centre-periphery process in terms of the increase of the differences between metropolis Sofia city and the other regions of the country processes that are much more intense than these in the other countries of Central and Eastern Europe. A particularly pronounced difference is observed in the intensive increase of the share of the population in the capital - an indicator that is three times higher than in other countries, (Totev S. 2014). 
Table 2. GDP structure by type of region at NUTS 3 (selected countries) \%

\begin{tabular}{|c|c|c|c|c|c|c|c|c|c|c|c|c|c|c|}
\hline \multirow{2}{*}{$\begin{array}{l}\text { Years } \\
\\
\\
\\
\\
\end{array}$} & \multicolumn{3}{|c|}{$\begin{array}{l}2000 \\
\text { GDP }\end{array}$} & \multicolumn{3}{|c|}{$\begin{array}{l}2013 \\
\text { GDP }\end{array}$} & \multicolumn{3}{|c|}{$\begin{array}{c}2013 \\
\begin{array}{c}\text { Relative share of the } \\
\text { territory }\end{array}\end{array}$} & \multicolumn{3}{|c|}{$\begin{array}{c}\text { GDP ratio to relative } \\
\text { share of territory for } \\
2013\end{array}$} & \multirow{2}{*}{ 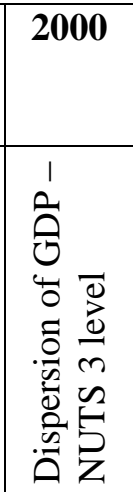 } & \multirow{2}{*}{ 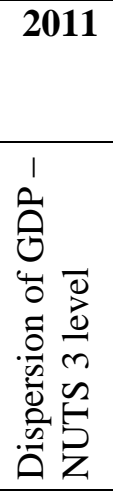 } \\
\hline & 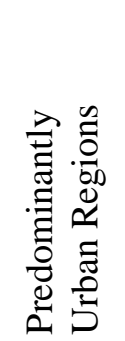 & 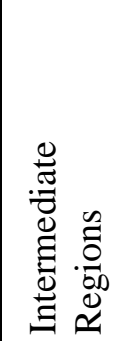 & 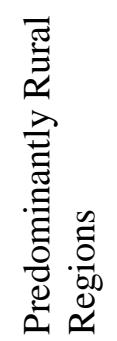 & 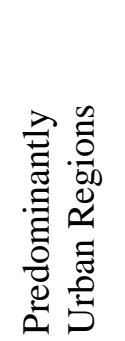 & 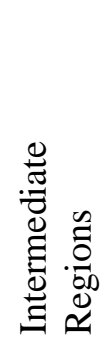 & 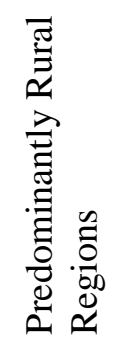 & 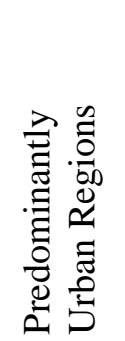 & 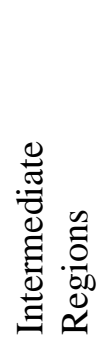 & 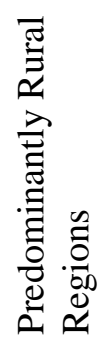 & 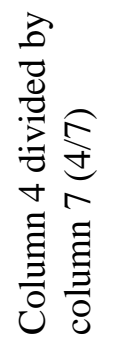 & 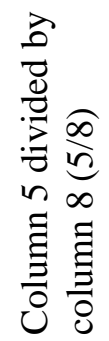 & 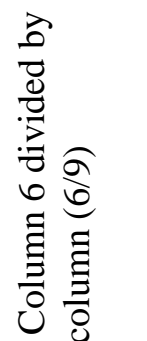 & & \\
\hline Columns & 1 & 2 & $\mathbf{3}$ & 4 & 5 & 6 & 7 & 8 & 9 & 10 & 11 & 12 & 13 & 14 \\
\hline$E U-28$ & -- & -- & -- & -- & -- & -- & 28,8 & 36,1 & 35,1 & -- & -- & -- & 25,9 & 28,3 \\
\hline Bulgaria & 25,6 & 63,3 & 11,1 & 39,3 & 51,6 & 9,1 & 1,2 & 76.7 & 22,1 & 32,8 & 0,7 & 0,4 & 27,3 & 45,5 \\
\hline Germany & 51,9 & 35,4 & 12,6 & 51,1 & 36,1 & 12,8 & 21,7 & 49,8 & 28,5 & 2,4 & 0,7 & 0,4 & 30,3 & 28,4 \\
\hline Estonia & 57,1 & 8,4 & 34,5 & 62,1 & 8,1 & 29,8 & 9,6 & 8,8 & 81,6 & 6,5 & 0,9 & 0,4 & 38,4 & 42,1 \\
\hline Greece & 54,3 & 18,8 & 26,8 & 56,6 & 18,0 & 25,3 & 5,7 & 28,3 & 66,0 & 9,9 & 0,6 & 0,4 & : & 27,0 \\
\hline Spain & 65,7 & 31,0 & 3,3 & 66,9 & 31,1 & 2,0 & 23,3 & 59,8 & 16,9 & 2,9 & 0,5 & 0,1 & 20,6 & 19,5 \\
\hline France & 44,8 & 29,1 & 26,1 & 47,8 & 27,9 & 24,3 & 8,8 & 28,6 & 62,6 & 5,4 & 1,0 & 0,4 & 23,9 & 26,9 \\
\hline Croatia & 29,4 & 33,3 & 37,3 & 33,1 & 32,8 & 34,0 & 4,8 & 14,3 & 80,9 & 6,9 & 2,3 & 0,4 & 30,4 & 35,0 \\
\hline Italy & 49,4 & 41,7 & 8,9 & 49,9 & 41,2 & 8,8 & 21,6 & 54,4 & 24,0 & 2,3 & 0,8 & 0,4 & 25,8 & 25,2 \\
\hline Latvia & 65,6 & 19,9 & 14,4 & 68,4 & 17,6 & 14,0 & 16,2 & 43,6 & 40,2 & 4,2 & 0,4 & 0,3 & 43,3 & 36,9 \\
\hline Lithuania & 36,0 & 58,3 & 5,7 & 39,4 & 55,2 & 5,4 & 14,9 & 71,5 & 13,6 & 2,6 & 0,8 & 0,4 & 21,0 & 24,8 \\
\hline Hungary & 34,9 & 51,5 & 13,6 & 37,8 & 50,1 & 12,1 & 37,8 & 50,1 & 12,1 & 7,6 & 1,7 & 0,2 & 38,9 & 44,0 \\
\hline Poland & 29,4 & 43,3 & 27,3 & 29,8 & 43,5 & 26,7 & 24,2 & 39,4 & 36,4 & 1,2 & 1,1 & 0,7 & 32,7 & 34,9 \\
\hline Portugal & -- & -- & -- & 54,8 & 18,5 & 26,7 & 20,0 & 13,3 & 66,7 & 2,7 & 1,4 & 0,4 & 27,8 & 27,9 \\
\hline Romania & 23,6 & 33,3 & 43,0 & 28,0 & 34,7 & 37,3 & 2,8 & 29,4 & 67,8 & 10,0 & 1,2 & 0,6 & 30,6 & 40,0 \\
\hline Slovakia & 24,8 & 45,4 & 29,8 & 28,1 & 43,0 & 29,0 & 4,2 & 49,8 & 46,0 & 6,7 & 0,9 & 0,6 & 27,8 & 35,2 \\
\hline United Kingdom & 77,8 & 19,6 & 2,6 & 77,8 & 19,5 & 2,6 & 28,2 & 42,3 & 29,5 & 2,8 & 0,5 & 0,1 & 30,2 & 32,5 \\
\hline $\begin{array}{l}\text { Average for the } \\
\text { observed countries }\end{array}$ & 44,7 & 35,5 & 19,8 & 48,2 & 33,1 & 18,7 & 15,3 & 38,9 & 43,4 & 6,7 & 1,0 & 0,4 & 29,9 & 32,9 \\
\hline
\end{tabular}

Source: Eurostat and Statistics in Focus 16/2013 (Eurostat edition). 
The share of GDP produced in urbanized regions is lowest in the new Central and East European countries that are with weaker economies (see columns 1 and 4 of Table 2) this is a result of the low share of territories that respond to the perceived criteria for urbanized regions in them - see column 7, Table 2. This relative share (column 7) is the lowest in Bulgaria because, according to Eurostat criteria only Sofia region is accepted as urban territory.

This is also the reason for the high share of GDP produced per unit of territory (column 10 $=$ ratio of columns 4/7) that shows approximately five times higher relative productivity for Bulgaria than the average for the observed countries (compare 32.8 for Bulgaria with the average 6, 7 in column 10). The relative productivity is determined by dividing the share of GDP produced for a given region (in this case metropolitan regions), to the share of employed in that region. The country with the highest relative performance after Bulgaria is Romania, with only 10 units. For the other two types of territory, average productivity remains close to the average for the observed EU countries.

Table 3 presents the level and dynamics of GDP and labour shares as well as the relative labour productivity of the regions corresponding to the Eurostat criteria for metropolitan regions

Table 3. Relative share of GDP and employed, relative labour productivity of the metropolitan regions in selected EU countries (\%)

\begin{tabular}{|c|c|c|c|c|c|c|c|c|c|}
\hline Years & \multicolumn{3}{|c|}{2000} & \multicolumn{3}{|c|}{2008} & \multicolumn{3}{|c|}{2013} \\
\hline Indicators & 仓ิ & 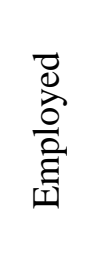 & 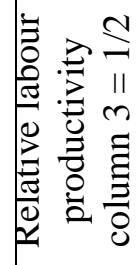 & 仓ิ & 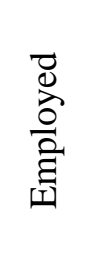 & 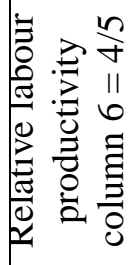 & Оิ & 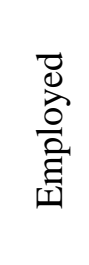 & 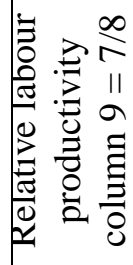 \\
\hline Columns & 1 & 2 & 3 & 4 & 5 & 6 & 7 & 8 & 9 \\
\hline Bulgaria * & 50 & 44 & 113,6 & 61 & 49 & 124,5 & 63 & 50 & 126,0 \\
\hline Czech Republic & 62 & 58 & 106,9 & 65 & 59 & 110,2 & 65 & 60 & 108,3 \\
\hline Greece & 54 & 47 & 114,9 & 57 & 49 & 116,3 & 57 & 48 & 118,8 \\
\hline Croatia & 46 & -- & -- & 48 & 46 & 104,4 & 49 & 47 & 104,3 \\
\hline Hungary & 60 & -- & -- & 63 & 59 & 106,8 & 63 & 58 & 108,6 \\
\hline Poland & 60 & 52 & 115,4 & 61 & 54 & 113,0 & 61 & 55 & 110,9 \\
\hline Portugal & -- & 49 & -- & -- & 49 & -- & 56 & 49 & 114,3 \\
\hline Romania & 49 & 37 & 132,4 & 53 & 40 & 132,5 & 56 & 40 & 140,0 \\
\hline Slovakia & 38 & 31 & 122,6 & 38 & 31 & 122,6 & 40 & 32 & 125,0 \\
\hline $\begin{array}{l}\text { Arithmetic } \\
\text { average }\end{array}$ & 52,4 & 45,4 & 117,6 & 55,8 & 48,4 & 116,3 & 56,7 & 48,8 & 117,4 \\
\hline
\end{tabular}

Source: Eurostat

* The metropolitan regions for Bulgaria are the districts of Sofia City, Plovdiv, Varna, Burgas

There are no major differences in GDP and labour shares and the relative productivity. The dynamics of Bulgaria and Romania of the productivity indicator is the highest. At the same time, what is specific for Bulgaria is that this increase in the relative productivity of the regions as a whole for Bulgaria is at the expense of the metropolis Sofia city. The data presented in Tables $\mathbf{2}$ and $\mathbf{3}$ identify the very high differences between the urbanized regions and especially the capital and the other regions in Bulgaria, compared to the similar differences in the other countries. This is and the main reason for the much higher regional disparities in Bulgaria compared to those in the other EU countries.

\section{SUMMARY}

The integration of the countries of SouthEastern Europe into the European open market is a major reason for increasing their regional disparities and affects mostly those with weaker economies. At the same time, these disparities have a far more negative impact on socio-economic indicators, especially in these countries creating even higher economic and social problems. The comparative analysis of the regional differences in Bulgaria with the EU countries identify the country as the one having the highest problems in this respect.

In a European Commission report presenting the challenges facing the EU's regions in 2020 (the "vulnerability index" of the regions) at 
NUTS 2 level ranked the regions according to their "climatic vulnerability", "energy vulnerability", "vulnerability to globalization" and "demographic vulnerability". The assessment was made at NUTS 2 level for the 268 EU regions. The worst-performing regions have a rank of 100 , and those with the best performance are ranked 0 . Other regions are located within these ranges, depending on the vulnerability indicator. For example, the Bulgarian Northwestern statistical region is the one that is most vulnerable in terms of demographic indicators and has a rank of 100 , see Reference IP / 08/1910 (2008).

The report highlights the need for all regions to find solutions at local level to address these challenges, according to the degree of their vulnerability.

The main conclusions of the report on regional disparities are:

- Significant variations due to globalization;

- Diversity in demographic patterns expressing in existing of serious problems for Central and Eastern Europe countries; - Wide-ranging impacts of climate change, mostly with negative economic effects; - High vulnerability of the peripheral regions mainly those in Eastern and Southern European countries.

In general, the statistical regions (NUTS 2 regions) in Bulgaria have the most unfavourable indicators in terms of observed indicators. Only for the climate vulnerability indicator the regions in Greece are expected to be worse affected than those in Bulgaria. This information, no matter that is somehow conditional, nevertheless gives a general picture of how problems that Bulgaria faces in its regional development are identified.

From a regional point of view, the coefficients of variation based on the ranks of the statistical regions for these indicators for Bulgaria are: $14 \%$ for climatic vulnerability; $12 \%$ for energy vulnerability; $25 \%$ for vulnerability to globalization and $41 \%$ for demographic vulnerability, which determines serious regional disparities, primarily as a result of globalization and, above all, of demographic vulnerability. This fact of high disparities, in light of the weakest overall indicators regarding vulnerability indices, highlights the seriousness of these interconnected problems with respect to Bulgaria's regional development compared to that of other EU countries.

\section{REFERENCES}

1. Totev, S., Regional convergence and economic growth, part of the annual report "Economic development and economic policy of Bulgaria: assessment and expectations - Special focus: inequality and poverty dynamics and policy for reduction, Economic Research Institute, GorexPress Sofia, pp. 113-127, 2014.

2. Totev, S. Economic integration and convergence in the EU Member States, Economic Thought, English Issue, pp. $68-86,2010$. 